\title{
13-Tungstoborate Stabilized by an Organostannoxane
}

\section{Hexamer}

\author{
Santiago Reinoso, Michael H. Dickman, Marius F. Matei and Ulrich Kortz* \\ School of Engineering and Science, Jacobs University Bremen, P.O. Box 750 561, 28725 Bremen, \\ Germany
}

Supporting Information

Figure S1. IR spectrum of $\mathrm{K}_{12}\left[\left\{\left(\mathrm{CH}_{3}\right)_{2} \mathrm{Sn}\right\}_{6}(\mathrm{OH})_{2} \mathrm{O}_{2}\left(\mathrm{H}_{2} \mathrm{BW}_{13} \mathrm{O}_{46}\right)_{2}\right] \cdot 32 \mathrm{H}_{2} \mathrm{O}(\mathbf{1 a})$.

Figure S2. TGA/DSC curves of $\mathrm{K}_{12}\left[\left\{\left(\mathrm{CH}_{3}\right)_{2} \mathrm{Sn}\right\}_{6}(\mathrm{OH})_{2} \mathrm{O}_{2}\left(\mathrm{H}_{2} \mathrm{BW}_{13} \mathrm{O}_{46}\right)_{2}\right] \cdot 32 \mathrm{H}_{2} \mathrm{O}$ (1a). 


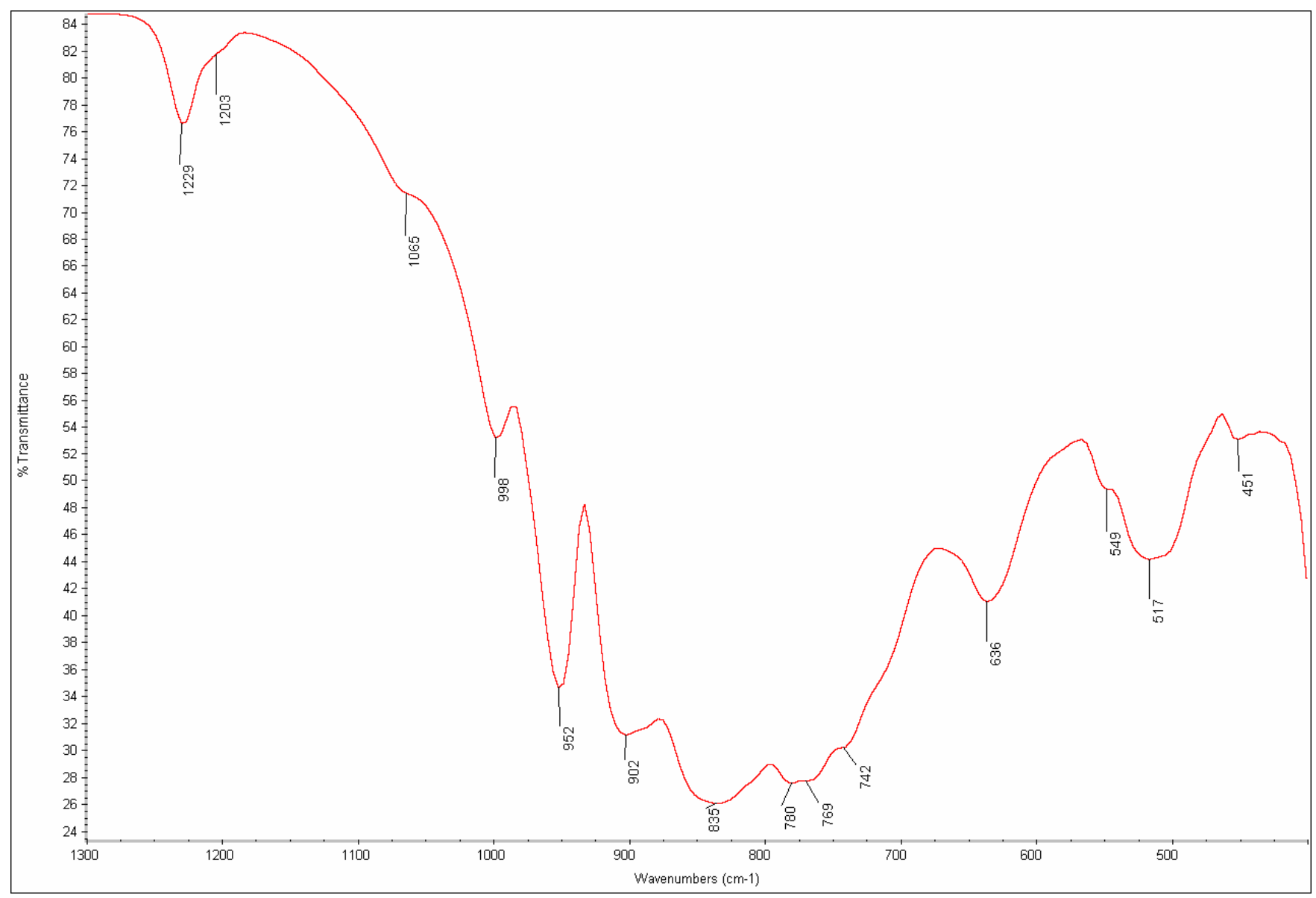

Figure S1 
Sample: [BW13DMT3]2-rep

Size: $15.4150 \mathrm{mg}$

Comment: repetition
File: C. ISDTSantiagol[Bw13DMT2-rep .001 Operator: BK

Run Date: 19-Dec-2006 16.25

Instrument: SDT Q600 V8.1 Build 99

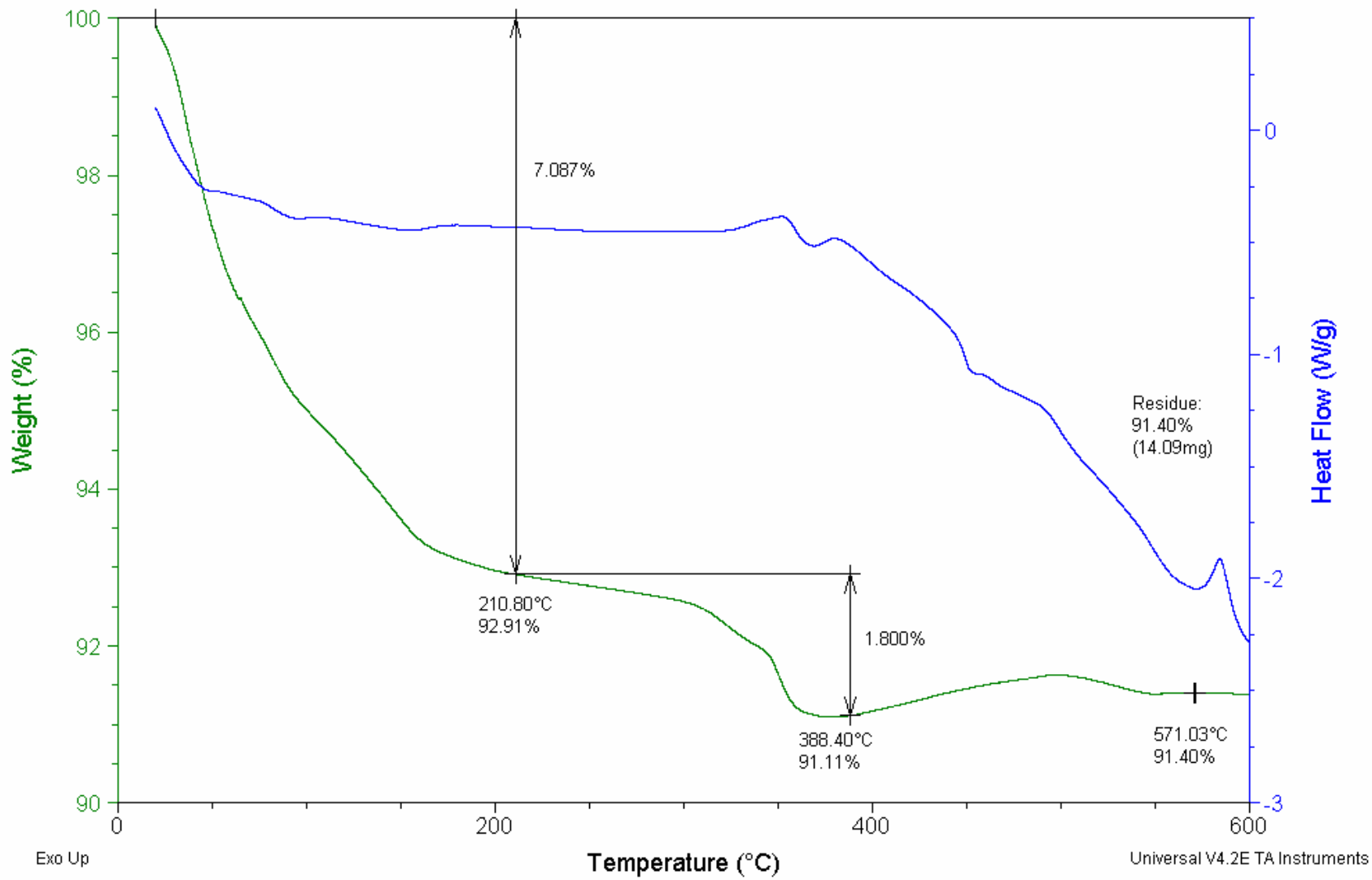

\section{Figure S2}

